TAO, Vol. 17, No. 2, 447-459, June 2006

\title{
An Empirical Study of Surface Wind Retrievals using the TMI over the South China Sea in the Summer Monsoon Season
}

\author{
Ching-Chung Li ${ }^{1, *}$ and Gin-Rong Liu ${ }^{2}$ \\ (Manuscript received 20 July 2005, in final form 16 February 2006)
}

\begin{abstract}
This study demonstrates the feasibility of an oceanic wind speed retrieval method: the D-matrix algorithm for local usage. The D-matrix algorithm was examined and ocean surface wind retrievals, utilizing the Tropical Rainfall Measuring Mission (TRMM) Microwave Imager (TMI), were validated by using wind speed measurements from ocean buoys deployed over the South China Sea from April to June of 1998 as part of the South China Sea Monsoon Experiment / 1998. Results showed the TMI D-matrix algorithm potentially malfunctioning in terms of no-rainfall recognition when summer monsoons prevail. In this study, assistance to its rain identification ability was conducted by using rain-screening methods for screening out non-rainfall TMI points. As to the quantitative validation, only cases of wind speed weaker than $15 \mathrm{~m} \mathrm{~s}^{-1}$ were analyzed with a root mean square of $1.34 \mathrm{~m} \mathrm{~s}^{-1}$. The study results are significant for local usage of the rainfall-profiling algorithm providing a scheme for estimating surface wind speeds over the South China Sea during the summer monsoon season.
\end{abstract}

(Key words: Wind speed retrieval, TMI, Summer monsoon, South China Sea)

\section{INTRODUCTION}

Ocean surface wind speed retrievals using passive microwave data are essential for the application of profiling algorithms for the estimation of rain rates using passive microwave measurements over open oceans where conventional stations are scarce. Since microwave

\footnotetext{
1 Department of Computer Science, Chung Cheng Institute of Technology, Taoyuan, Taiwan, ROC

${ }^{2}$ Center for Space and Remote Sensing Research, National Central University, Chung-Li, Taiwan, $\mathrm{ROC}$

* Corresponding author address. Prof. Ching-Chung Li, Department of Computer Science, Chung Cheng Institute of Technology, Taoyuan, Taiwan, ROC; E-mail: ocean@ccit.edu.tw
} 
brightness temperature dependence on the sea state (wind speed) arises from surface roughness and sea foam effects (Hollinger 1971), we can estimate surface wind speed by measuring the amount of microwave energy emitted from the ocean surface. However, total upwelling microwave emissions contain radiation contributed by liquid phase hydrometeors within the atmosphere. This doesn't necessarily propose a problem for microwave-emission based measurement of wind speed so long as the rate of change in radiation sensed by passive microwave radiometer is evidently affected by wind driven surface variation. The technique depends on the microwave channels used for wind speed retrievals. It cannot be used, however, during rainy conditions as radiation variation sensed by passive microwave radiometer is dominated by the variation in rain rates over the oceans.

The launch of the Tropical Rainfall Measuring Mission (TRMM) satellite in November of 1997 provided significantly improved oceanic wind retrieval capability. The TRMM's loweraltitude orbit and its 35-degree inclination to the Equator results in better spatial resolution and fewer beam-filling problems than the Defense Meteorological Satellite Program (DMSP). The DMSP was launched in 1987 with the first Special Sensor Microwave Imager (SSM/I) aboard. The TRMM microwave Imager (TMI) is an improvement over the SSM/I in two important regards. Firstly, it utilizes a dual-polarized pair of $10.7 \mathrm{GHz}$ channels that increase the dynamic range of rainfall estimates. Secondly, a slight change in the water vapor channel frequency to $21.3 \mathrm{GHz}$ reduces saturation in the humid tropics. This makes the TMI a ninechannel passive radiometer with dual-polarized channels at 10.7, 19.4, 37.0 and $85.5 \mathrm{GHz}$ and a vertical polarization channel at $21.3 \mathrm{GHz}$ (Simpson et al. 1996, Kummerow et al. 1998).

A year-long analysis of TMI microwave brightness temperature data is presented by Connor and Chang (2000) with regard to the retrieval of ocean surface wind speeds using standard regression techniques with in situ ocean buoy measurements during 1998. Ground truth data were recorded from 25 National Oceanic and Atmospheric Administration (NOAA) Data Buoy Center offshore buoys. Most of the buoy wind speeds in the match up data set were below $15 \mathrm{~m} \mathrm{~s}^{-1}$. They made use of microwave brightness temperature dependence on wind speed and modified the global D-matrix algorithm (Goodberlet et al. 1990), which was developed for the SSM/I for estimating ocean surface wind speed, using data from the TMI. A form of the D-matrix algorithm is shown in Equation (1). Particular emphasis was placed on the use of the $10.7 \mathrm{GHz}$ channels in overcoming contamination in brightness temperature measurements at 19.4, 21.3, and $37.0 \mathrm{GHz}$ caused by precipitation and water vapor in the propagation path.

$\mathrm{WSc}=\mathrm{C}_{0}+\mathrm{C}_{1} \mathrm{~Tb} 10.7 \mathrm{~V}+\mathrm{C}_{2} \mathrm{~Tb} 10.7 \mathrm{H}+\mathrm{C}_{3} \mathrm{~Tb} 19.4 \mathrm{~V}+\mathrm{C}_{4} 21.3 \mathrm{~V}+\mathrm{C}_{5} \mathrm{~Tb} 37 \mathrm{~V}+\mathrm{C}_{6} \mathrm{~Tb} 37 \mathrm{H}$

Where WSc is ocean surface wind speed; and Tb variables are brightness temperatures for their respective TMI dual-polarized channels. $\mathrm{C}_{0,1,2 \ldots 6}$ are new D-matrix coefficients determined from standard multiple-variable linear regression analysis (see Table 1). D-matrix rain flags $0,1,2$, and 3 were dedicated to identify: non-rainfall conditions, conditions of moderately higher interference, possible rain, and active rain categories, respectively. These flags were predetermined according to the thresholds for $\mathrm{Tb} 19.4 \mathrm{H}$, and the difference between $\mathrm{Tb} 37 \mathrm{~V}$ and $\mathrm{Tb} 37 \mathrm{H}$. Table 2 shows rain-flag definitions for the D-matrix algorithm developed for the 
Table 1. TMI D-matrix coefficients.

\begin{tabular}{cr}
\hline Coefficient & \multicolumn{1}{c}{ Value } \\
\hline $\mathrm{C}_{0}$ & 105.3520 \\
$\mathrm{C}_{1}$ & 0.2418 \\
$\mathrm{C}_{2}$ & 0.3218 \\
$\mathrm{C}_{3}$ & -0.0292 \\
$\mathrm{C}_{4}$ & -0.0124 \\
$\mathrm{C}_{5}$ & -1.1742 \\
$\mathrm{C}_{6}$ & 0.5742 \\
\hline
\end{tabular}

Table 2. Rain flag definitions of the D-matrix algorithms.

\begin{tabular}{ccc}
\hline Rain Flag & SSM/I D-matrix Algorithm & TMI D-matrix Algorithm \\
\hline 0 & Tb37V $-\mathrm{Tb} 37 \mathrm{H}>50 \mathrm{~K}$ & Tb37V $-\mathrm{Tb} 37 \mathrm{H}>42 \mathrm{~K}$ \\
& and $\mathrm{Tb} 19.4 \mathrm{H}<165 \mathrm{~K}$ & and Tb19.4H $<200 \mathrm{~K}$ \\
1 & $37 \mathrm{~K} \leq \mathrm{Tb} 37 \mathrm{~V}-\mathrm{Tb} 37 \mathrm{H}<50 \mathrm{~K}$ & $37 \mathrm{~K} \leq \mathrm{Tb} 37 \mathrm{~V}-\mathrm{Tb} 37 \mathrm{H}<42 \mathrm{~K}$ \\
& or Tb19.4H $\geq 165 \mathrm{~K}$ & or Tb19.4H $\geq 200 \mathrm{~K}$ \\
2 & $30 \mathrm{~K} \leq \mathrm{Tb} 37 \mathrm{~V}-\mathrm{Tb} 37 \mathrm{H}<37 \mathrm{~K}$ & $30 \mathrm{~K} \leq \mathrm{Tb} 37 \mathrm{~V}-\mathrm{Tb} 37 \mathrm{H}<37 \mathrm{~K}$ \\
3 & $\mathrm{~Tb} 37 \mathrm{~V}-\mathrm{Tb} 37 \mathrm{H}<30 \mathrm{~K}$ & $\mathrm{~Tb} 37 \mathrm{~V}-\mathrm{Tb} 37 \mathrm{H}<30 \mathrm{~K}$ \\
\hline
\end{tabular}

SSM/I (Goodberlet et al. 2000) and for the new D-matrix algorithm developed for the TMI (Connor and Chang 2000). In comparison with the use of the SSM/I D-matrix algorithm, results of wind retrieval using the TMI data as inputs show a $21 \%$ increase in acceptable data samples using the TMI D-matrix algorithm.

Since the microwave wind retrieval algorithm only works under rain-free conditions, its ability to accurately recognize such conditions (rain flags) decides its success. The feasibility of applying the TMI wind speed retrieval technique over the South China Sea during the summer monsoon season, which is characterized by monsoon rains, needs to be examined carefully before its application. Therefore, the purpose of this study is to demonstrate the 
feasibility of the D-matrix algorithm for local usage, and in turn, establish a scheme for using this algorithm to retrieve ocean- surface-wind speed using TMI data.

During the summer monsoon season of 1998, the South China Sea Monsoon Experiment (SCSMEX) was conducted. Validation of TMI wind-speed retrievals was conducted from April to June of 1998 using surface wind speed measurements from two open ocean buoys deployed over the region. The procedures for this validation were separated into two parts. Firstly, the rain-recognition ability of different rain-recognition methodologies were examined. Secondly, a quantitative validation of the TMI D-matrix algorithm was conducted. As has been discussed, the TMI D-matrix algorithm may fail in rain-scene recognition during monsoon rains hence assistance was given to its rain identification ability in this study by using screening methods to screen out non-rainfall TMI points.

\section{DATA}

During the SCSMEX, two acoustic rain gauges (ARGs) were mounted at $20 \mathrm{~m}$ and $22 \mathrm{~m}$ depths on a mooring mounted beneath an Autonomous Temperature Line Acquisition System (ATLAS) buoy deployed at $20.37^{\circ} \mathrm{N}, 116.52^{\circ} \mathrm{E}$ (Fig. 1). The mooring deployment lasted from April 7 to June 6 of 1998. The surface wind speed measurements used here were from the ARG at $20 \mathrm{~m}$, provided by Dr. J. A. Nystuen, the Applied Physics Laboratory, University of Washington, US. The categories for weather classification were: wind only, rain, drizzle or noise according to the weather classification algorithm presented by Nystuen and Selsor (1997) using passive acoustic drifters. Time steps for the data were not uniform: when "wind only" conditions were detected, the next acoustic sample recorded 5 minutes later; when "drizzle" was detected, the next sample recorded 1 minute later; when "rain" was detected the next sample recorded 30 seconds later. Acoustic wind speed estimates were not available during periods of rain. When the weather code indicates rain or noise, the wind-speed estimate was set to zero, which means "no data". The minimum wind speed reported by the ARGs was $4 \mathrm{~m} \mathrm{~s}^{-1}$.

Another ATLAS rain buoy, the SCS3, was deployed at $12.98^{\circ} \mathrm{N}, 114.41^{\circ} \mathrm{E}$ (Fig. 1), which provided surface meteorological measurements such as wind velocity and rain accumulation as part of the SCSMEX. The buoy data used in this study were provided by Dr. David Tang, the Department of Oceanography, National Taiwan University. The period of data used in this study was from April 14 to June 30; time step for the wind-velocity data was 10 minutes.

The TMI data used in this study were level-1B11 low-resolution data, which were instrument data in full resolution with calibration and Earth location computed (Simpson et al. 1996). The data were used for estimating surface wind speeds for Equation (1). The measurements of wind speed from two open ocean buoys (ARG and SCS3) represented the ground truth corresponding with TMI wind speed retrievals. The along-track length of the effective field of view was $9.1 \mathrm{~km}$ for channels at 10.7, 19.4, 21.3, and $37.0 \mathrm{GHz}$ (Kummerow et al. 1998). In this study, the spatial criterion for comparison is the distance from the center of the TMI point to the buoy, which was set at less than $4.5 \mathrm{~km}$. Since frequencies of wind measurements were not longer than 10 minutes for both buoys, the closest wind speed records represented the ground truth for comparison with the TMI wind speed retrievals. 


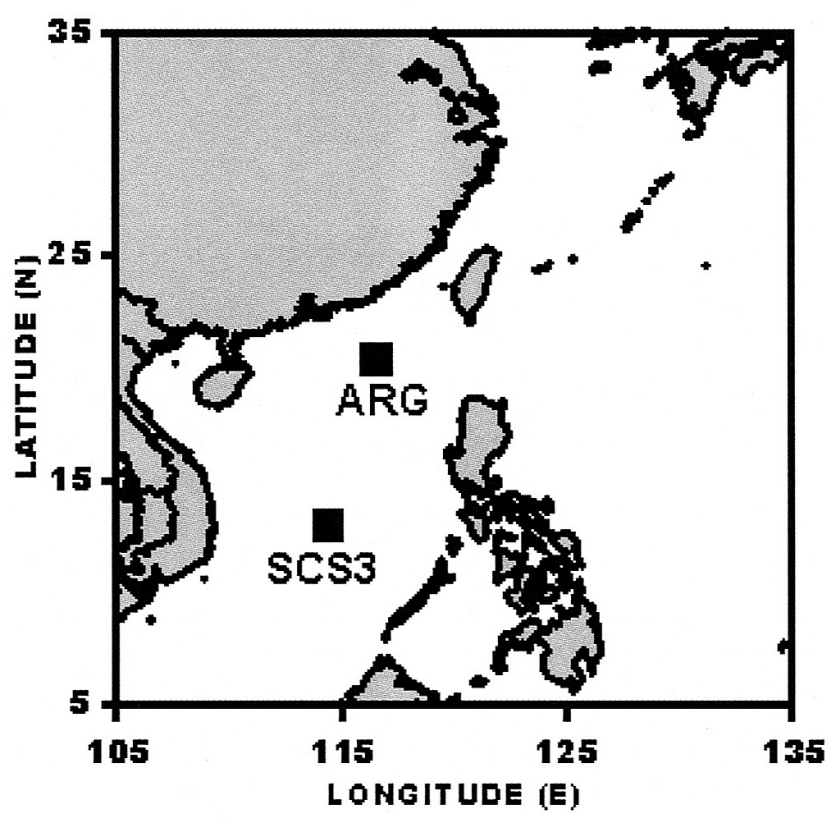

Fig. 1. The locations of the acoustic rain gauge (ARG) and the ATLAS rain buoy (SCS3).

\section{SCREENING METHODOLOGIES}

Together with buoy observations, this study applied two screening methodologies using microwave measurements for screening out rain-free regions to validate the ability of rain recognition for both the SSM/I D-matrix algorithm and TMI D-matrix algorithm.

The first method used was the Scattering Index (SI) method developed for SSM/I rainrate estimation technique to recognize rainy scenes over oceans (Goodberlet et al. 1990). Using multi-channel microwave data from the SSM/I, Grody (1991) applied a decision tree method to classify snow cover and precipitation. His rain classification method was improved upon by Ferraro et al. (1994) for presenting the effects of surface conditions on rain identification. After identifying sea-ice signals, with the regression formula shown in Equation (2), the SI was computed using three vertically polarized SSM/I data over oceans. The Tb variables in Equation (2) are brightness temperatures for SSM/I dual polarized channels. For global application, a value of SI greater than $10 \mathrm{~K}$ indicates the presence of both scattering and emission due to rain, and generally corresponds to rain rates of $1 \mathrm{~mm} \mathrm{~h}^{-1}$ or greater.

$$
\mathrm{SI}=-174.4+0.72 \mathrm{~Tb} 19 \mathrm{~V}+2.439 \mathrm{~Tb} 22 \mathrm{~V}-0.00504 \mathrm{~Tb} 22 \mathrm{~V}^{2}-\mathrm{Tb} 85 \mathrm{~V}
$$

The second method used was the CL method developed by Chen and Li (2000), dedicated 
to the estimation of rainfalls occurring during the Mei-Yu season when summer monsoons prevail. Regarding emission-based rainfall mechanisms and according to non-rainfall event statistics from isolated islands located at regions near Taiwan or Okinawa, the mean brightness temperatures of TMI dual-polarized channels at $10.7 \mathrm{GHz}$ through $21.3 \mathrm{GHz}$ were treated as rain thresholds for oceanic rain rate retrievals. Table 3 shows the rainy criteria used in this study. A rainy scene ensues when any TMI level-1B11 point has a brightness temperature larger than its threshold for TMI onboard channels of $10.7 \mathrm{GHz}$ through $21.3 \mathrm{GHz}$.

Table 3. The screening method presented by Chen and $\mathrm{Li}$ (2000).

\begin{tabular}{cc}
\hline Channel (GHz) & Rainy Criteria \\
\hline $10.7(\mathrm{~V})$ & $\mathrm{Tb} 10.7 \mathrm{~V}>178 \mathrm{~K}$ \\
$10.7(\mathrm{H})$ & $\mathrm{Tb} 10.7 \mathrm{H}>103 \mathrm{~K}$ \\
$19.4(\mathrm{~V})$ & $\mathrm{Tb} 19.4 \mathrm{~V}>217 \mathrm{~K}$ \\
$19.4(\mathrm{H})$ & $\mathrm{Tb} 19.4 \mathrm{H}>165 \mathrm{~K}$ \\
$21.3(\mathrm{~V})$ & $\mathrm{Tb} 21.3 \mathrm{~V}>246 \mathrm{~K}$ \\
\hline
\end{tabular}

\section{VALIDATION RESULTS}

Technique validation procedures were separated into two parts. Firstly, the rain-recognition ability of different rain-recognition methodologies, i.e., the SSM/I D-matrix algorithm, the TMI D-matrix algorithm, the SI method, and the CL method, was examined. To this end, the SI was computed using TMI data with Tb variables being brightness temperatures for respective TMI dual-polarized channels in Equation (2)

The second part of the validation process involved quantitative validation of the TMI Dmatrix algorithm. Tables 4 and 5 show comparison results between TMI wind speed retrievals and wind speed measurements from the ARG and the SCS3 buoy, respectively. Within Table 4, WSc represents the retrieved wind speed computed using the TMI wind retrieval technique presented by Connor and Chang (2000). WSa represents the wind speed observed by the ARG. In addition, $C D$ represents the $A R G$ weather code. There are six acoustic weather codes $(C D)$ : $0=$ wind only (rain free), $1=$ heavy rain, $2=$ drizzle, $3=$ noise (shipping), $4=$ noise (unknown source), $5=$ noise (spike in spectrum). As shown in Table 2, RFt and RFs stand for the rain flags determined by the TMI and SSM/I D-matrix algorithms, respectively. CL was determined by the CL method for identifying TMI rainy pixels (CL: $1=$ rain, $0=$ rain free). TMI pixels with SI values larger than $10 \mathrm{~K}$ were classified as rainy scenes with rain rates heavier than $1 \mathrm{~mm} \mathrm{~h}^{-1}$. The abbreviation WSb, in Table 5, stands for surface wind speed observations from the SCS3 buoy and CD the weather type observed by the SCS3 buoy (CD: $1=$ rain, $0=$ rain free). 
Table 4. The statistics of wind observations from the ARG deployed at (20. $37^{\circ} \mathrm{N}, 116.52^{\circ} \mathrm{E}$ ) corresponding with the TRMM overpasses. The meanings of these abbreviations shown in the table are described in the text. (ND $=$ ARG wind speed is smaller than $4 \mathrm{~m} \mathrm{~s}^{-1}$ )

\begin{tabular}{|c|c|c|c|c|c|c|c|c|c|c|c|c|c|c|c|}
\hline No. & RFt & RFs & SI & CL & CD & $\begin{array}{c}\text { WSc } \\
(\mathrm{m} / \mathrm{s})\end{array}$ & $\begin{array}{r}\text { WSa } \\
(\mathrm{m} / \mathbf{s})\end{array}$ & No. & RFt & RFs & SI & CL & CD & $\begin{array}{c}\text { WSc } \\
(\mathrm{m} / \mathrm{s})\end{array}$ & $\begin{array}{c}\text { WSa } \\
(\mathrm{m} / \mathrm{s})\end{array}$ \\
\hline 1 & 0 & 0 & -2.3 & 0 & 0 & 3.32 & ND & 38 & 0 & 0 & -2.2 & 0 & 0 & 5.93 & 5.65 \\
\hline 2 & 0 & 0 & 0.2 & 0 & 0 & 3.55 & ND & 39 & 0 & 0 & -1.5 & 0 & 0 & 5.38 & ND \\
\hline 3 & 0 & 0 & -4.4 & 0 & 0 & 3.69 & ND & 40 & 0 & 0 & -3.6 & 0 & 0 & 4.73 & 4.32 \\
\hline 4 & 0 & 0 & -3.4 & 0 & 0 & 3.84 & ND & 41 & 0 & 0 & -2.1 & 0 & 0 & 2.15 & ND \\
\hline 5 & 0 & 0 & -0.1 & 0 & 0 & 4.13 & 4.88 & 42 & 0 & 0 & -2.1 & 0 & 0 & 1.62 & ND \\
\hline 6 & 0 & 1 & 2.2 & 0 & 0 & 11.66 & 5.78 & 43 & 0 & 0 & -0.9 & 0 & 0 & 3.72 & 5.36 \\
\hline 7 & 0 & 1 & -0.8 & 0 & 0 & 11.00 & 6.97 & 44 & 0 & 0 & -4.6 & 0 & 0 & 3.88 & ND \\
\hline 8 & 0 & 1 & 2.2 & 0 & 0 & 7.00 & 4.25 & 45 & 0 & 0 & -2.8 & 0 & 0 & 1.90 & ND \\
\hline 9 & 0 & 1 & -1.8 & 0 & 0 & 4.09 & ND & 46 & 0 & 0 & -3.2 & 0 & 0 & 0.94 & ND \\
\hline 10 & 0 & I & -2.7 & 0 & 0 & 6.43 & 7.49 & 47 & 1 & 1 & 70.4 & 1 & 1 & Rain & Rain \\
\hline 11 & 0 & 1 & 3.7 & 0 & 0 & 6.83 & 5.90 & 48 & 0 & 1 & 1.3 & 1 & 0 & 6.32 & ND \\
\hline 12 & 0 & I & 2.3 & 0 & 0 & 2.12 & ND & 49 & 0 & 1 & 4.2 & 1 & 0 & 8.60 & ND \\
\hline 13 & 0 & 0 & 0.1 & 0 & 0 & 7.72 & 7.46 & 50 & 0 & 1 & -0.8 & 0 & 0 & 5.73 & ND \\
\hline 14 & 0 & 1 & -0.7 & 0 & 0 & 8.34 & 7.94 & 51 & 1 & 1 & 16.0 & 1 & 0 & 15.52 & ND \\
\hline 15 & 0 & 1 & -1.3 & 0 & 0 & 11.46 & 10.37 & 52 & 0 & 1 & 1.5 & 0 & 0 & 5.91 & 5.54 \\
\hline 16 & 0 & 1 & 3.2 & 0 & 0 & 6.21 & $\mathrm{ND}$ & 53 & 2 & 1,2 & 32.9 & 1 & 0 & 16.46 & 5.66 \\
\hline 17 & 0 & 0 & 0.6 & 0 & 0 & 1.89 & ND & 54 & 0 & 1 & 0.7 & 0 & 0 & 3.05 & ND \\
\hline 18 & 0 & 0 & -1.8 & 0 & 0 & 4.71 & ND & 55 & 0 & 1 & -1.8 & 0 & 0 & 4.17 & 4.02 \\
\hline 19 & 0 & 0 & 1.1 & 0 & 0 & 5.25 & 6.62 & 56 & 0 & 1 & 0.2 & 0 & 5 & 4.49 & Noise \\
\hline 20 & 0 & 0 & -2.2 & 0 & 0 & 4.87 & 5.57 & 57 & 0 & 1 & -1.9 & 0 & 0 & 5.77 & 5.64 \\
\hline 21 & 0 & 0 & -3.4 & 0 & 0 & 4.06 & 4.33 & 58 & 0 & 1 & -1.8 & 0 & 0 & 4.88 & ND \\
\hline 22 & 0 & 0 & -3.5 & 0 & 0 & 3.76 & ND & 59 & 0 & 1 & -2.1 & 0 & 0 & 5.04 & 4.33 \\
\hline 23 & 0 & 1 & -8.0 & 0 & 0 & 5.21 & 5.34 & 60 & 0 & 1 & 2.5 & 0 & 0 & 5.32 & ND \\
\hline 24 & 0 & 0 & -1.6 & 0 & 0 & 2.78 & ND & 61 & 1 & 1 & -0.8 & 0 & 0 & 11.15 & 9.79 \\
\hline 25 & 1 & 1 & 35.7 & 1 & 1 & Rain & Rain & 62 & 1 & 1 & -1.5 & 0 & 0 & 7.96 & 7.81 \\
\hline 26 & 0 & 0 & 1.5 & 0 & 0 & 4.98 & ND & 63 & 0 & 0 & -1.9 & 0 & 4 & 6.52 & Noise \\
\hline 27 & 0 & 1 & 4.4 & 0 & 0 & 7.58 & 7.43 & 64 & 0 & 0 & -2.1 & 0 & 0 & 5.10 & 5.92 \\
\hline 28 & 0 & 1 & 1.2 & 0 & 0 & 5.76 & ND & 65 & 0 & 1 & -1.4 & 0 & 0 & 4.36 & 5.64 \\
\hline 29 & 0 & 1 & -1.3 & 0 & 0 & 4.00 & ND & 66 & 0 & 1 & 1.4 & 0 & 0 & 7.21 & 4.99 \\
\hline 30 & 0 & 0 & -0.1 & 0 & 0 & & 5.13 & 67 & 0 & 1 & 1.8 & 1 & 0 & 9.57 & ND \\
\hline 31 & 0 & 0 & -1.9 & 0 & 0 & & 5.79 & 68 & 0 & 1 & 1.2 & 0 & 5 & 6.40 & Noise \\
\hline 32 & 0 & 1 & -0.8 & 0 & 0 & 5.72 & 5.74 & 69 & 0 & 1 & -0.1 & 0 & 0 & 5.48 & 6.00 \\
\hline 33 & 0 & 0 & -2.5 & 0 & 0 & & ND & 70 & 1 & I & 0.8 & 0 & 0 & 7.45 & 6.89 \\
\hline 34 & 0 & 1 & 4.3 & 1 & 0 & 11.78 & ND & 71 & 0 & 1 & 2.8 & 1 & 4 & 9.40 & Noise \\
\hline 35 & 0 & 1 & 0.3 & 0 & 0 & 5.4 & ND & 72 & 0 & 1 & -1.3 & 0 & 0 & 5.03 & 7.35 \\
\hline 36 & 0 & 0 & -0.4 & 0 & 0 & 4.64 & 7.59 & 73 & 0 & 1 & -0.1 & 0 & 0 & 6.67 & ND \\
\hline 37 & 0 & 0 & -3.1 & 0 & 0 & 3.51 & 4.58 & 74 & 0 & 1 & 0.3 & 0 & 0 & 5.37 & 5.16 \\
\hline
\end{tabular}


Table 5. The statistics of wind measurements from the SCS3 buoy deployed at $\left(12.98^{\circ} \mathrm{N}, 114.41^{\circ} \mathrm{E}\right)$ corresponding with the TRMM overpasses. (ND = no wind speed data)

\begin{tabular}{|c|c|c|c|c|c|c|c|c|c|c|c|c|c|c|c|}
\hline \multirow{2}{*}{$\frac{\text { No. }}{\frac{1}{1}}$} & \multicolumn{2}{|c|}{ RFt RFs } & \multirow{2}{*}{$\begin{array}{c}\text { SI } \\
0.3\end{array}$} & \multirow{2}{*}{$\frac{\mathbf{C L}}{0}$} & \multirow{2}{*}{$\frac{C D}{0}$} & \multicolumn{2}{|c|}{$\begin{array}{l}\text { WSc WSb } \\
(\mathrm{m} / \mathrm{s})(\mathrm{m} / \mathrm{s})\end{array}$} & \multirow{2}{*}{$\frac{\text { No. }}{41}$} & \multicolumn{2}{|c|}{ RFt RFs } & \multirow{2}{*}{$\begin{array}{c}\text { SI } \\
-0.7\end{array}$} & \multirow{2}{*}{$\begin{array}{c}\text { CL } \\
0\end{array}$} & \multirow{2}{*}{$\frac{\text { CD }}{0}$} & \multicolumn{2}{|c|}{$\begin{array}{l}\text { WSc WSb } \\
(\mathrm{m} / \mathrm{s})(\mathrm{m} / \mathrm{s})\end{array}$} \\
\hline & 0 & 1 & & & & 7.05 & 3.10 & & 0 & 1 & & & & 7.40 & 7.49 \\
\hline 2 & 0 & 0 & -2.0 & 0 & 0 & 4.36 & 1.21 & 42 & 1 & 1 & 4.2 & 0 & 0 & 8.66 & 9.57 \\
\hline 3 & 0 & 1 & -0.4 & 0 & 0 & 6.46 & 2.23 & 43 & 1 & 1 & 55.6 & 1 & 1 & Rain & 1.39 \\
\hline 4 & 0 & 0 & -0.1 & 0 & 0 & 7.70 & 3.40 & 44 & 0 & 1 & 1.1 & 0 & 0 & 6.33 & 5.62 \\
\hline 5 & 0 & 0 & 0.0 & 0 & 0 & 6.42 & 3.04 & 45 & 1 & 1 & -0.1 & 0 & 0 & 7.99 & 7.47 \\
\hline 6 & 0 & 1 & -1.9 & 0 & 0 & 3.14 & 3.59 & 46 & 0 & 1 & -0.2 & 0 & 0 & 6.06 & 5.96 \\
\hline 7 & 0 & 1 & 3.1 & 1 & 0 & 8.48 & 5.68 & 47 & 0 & 1 & 0.8 & 0 & 0 & 6.99 & 8.52 \\
\hline 8 & 0 & 0 & -3.4 & 0 & 0 & 2.82 & 4.04 & 48 & 0 & 1 & 0.6 & 0 & 0 & 9.12 & 8.05 \\
\hline 9 & 0 & 0 & -2.4 & 0 & 0 & 3.69 & 1.89 & 49 & 0 & 1 & 0.3 & 0 & 0 & 7.58 & 7.79 \\
\hline 10 & 0 & 0 & -3.3 & 0 & 0 & 5.24 & 3.68 & 50 & 0 & 1 & 3.8 & 0 & 0 & 8.96 & 6.53 \\
\hline 11 & 0 & 0 & -2.8 & 0 & 0 & 3.24 & 2.30 & 51 & 0 & 1 & 1.2 & 0 & 0 & 6.03 & 7.67 \\
\hline 12 & 0 & 0 & -3.7 & 0 & 0 & 5.71 & 3.75 & 52 & 0 & 0 & -1.6 & 0 & 0 & 4.51 & 6.44 \\
\hline 13 & 0 & 0 & -4.2 & 0 & 0 & 4.40 & 4.52 & 53 & 0 & 0 & -3.0 & 0 & 0 & 5.35 & 5.42 \\
\hline 14 & 0 & 1 & -1.1 & 0 & 0 & 7.50 & 6.69 & 54 & 0 & 1 & 0.5 & 0 & 0 & 4.82 & 6.05 \\
\hline 15 & 0 & 1 & 3.0 & 0 & 0 & 8.40 & 5.62 & 55 & 0 & 0 & 0.1 & 0 & 0 & 5.02 & ND \\
\hline 16 & 0 & 0 & -1.1 & 0 & 0 & 5.32 & 3.32 & 56 & 0 & 0 & -4.7 & 0 & 0 & 2.91 & ND \\
\hline 17 & 0 & 0 & -1.8 & 0 & 0 & 3.52 & 3.00 & 57 & 0 & 1 & -3.3 & 0 & 0 & 4.35 & ND \\
\hline 18 & 0 & 0 & -3.9 & 0 & 0 & 2.96 & 3.21 & 58 & 0 & 1 & -1.9 & 0 & 0 & 5.63 & ND \\
\hline 19 & 0 & 0 & -1.6 & 0 & 0 & 3.89 & 3.42 & 59 & 0 & 1 & -1.5 & 0 & 0 & 6.57 & ND \\
\hline 20 & 0 & 0 & -2.4 & 0 & 0 & 4.92 & 4.35 & 60 & 0 & 1 & -1.7 & 0 & 0 & 4.66 & 5.46 \\
\hline 21 & 0 & 0 & -3.2 & 0 & 0 & 5.31 & 4.60 & 61 & 0 & 1 & -1.7 & 0 & 0 & 4.28 & 4.10 \\
\hline 22 & 0 & 0 & -0.3 & 0 & 0 & 3.47 & 4.85 & 62 & 0 & 1 & -0.4 & 0 & 0 & 6.57 & 4.82 \\
\hline 23 & 0 & 0 & -3.9 & 0 & 0 & 5.19 & 4.72 & 63 & 0 & 1 & -0.8 & 0 & 0 & 5.86 & 3.90 \\
\hline 24 & 0 & 0 & -2.6 & 0 & 0 & 5.52 & 6.24 & 64 & 0 & 1 & -0.4 & 0 & 0 & 3.96 & 3.60 \\
\hline 25 & 0 & 0 & -3.4 & 0 & 0 & 5.52 & 5.79 & 65 & 0 & 1 & -1.9 & 0 & 0 & 4.35 & 5.20 \\
\hline 26 & 0 & 0 & -2.0 & 0 & 0 & 6.96 & 5.99 & 66 & 0 & 1 & -2.1 & 0 & 0 & 5.47 & 5.38 \\
\hline 27 & 0 & 0 & -1.8 & 0 & 0 & 4.29 & 4.35 & 67 & 0 & 1 & 0.3 & 0 & 0 & 5.03 & 5.89 \\
\hline 28 & 0 & 0 & -2.0 & 0 & 0 & 3.83 & 4.68 & 68 & 0 & 1 & -0.6 & 0 & 0 & 6.44 & ND \\
\hline 29 & 0 & 0 & -1.4 & 0 & 0 & 4.79 & 3.90 & 69 & 3 & 1, 3 & 4.9 & 0 & 0 & 8.07 & ND \\
\hline 30 & 0 & 0 & -0.6 & 0 & 0 & 6.39 & 6.06 & 70 & 1 & 1 & 3.8 & 0 & 0 & 7.76 & ND \\
\hline 31 & 0 & 1 & -4.1 & 0 & 0 & 5.45 & 5.62 & 71 & 0 & 1 & -1.0 & 0 & 0 & 4.33 & ND \\
\hline 32 & 0 & 0 & -2.3 & 0 & 0 & 4.22 & 3.42 & 72 & 0 & 1 & -0.1 & 0 & 0 & 4.67 & ND \\
\hline 33 & 0 & 0 & -3.4 & 0 & 0 & 2.53 & 3.00 & 73 & 0 & 1 & -1.9 & 0 & 0 & 4.27 & ND \\
\hline 34 & 0 & 0 & -2.4 & 0 & 0 & 4.43 & 4.85 & 74 & 0 & 1 & -0.3 & 0 & 0 & 4.22 & ND \\
\hline 35 & 0 & 0 & -3.6 & 0 & 0 & 1.66 & 1.12 & 75 & 0 & 1 & 3.1 & 0 & 0 & 5.39 & ND \\
\hline 36 & 0 & 0 & -4.1 & 0 & 0 & 3.04 & 3.36 & 76 & 0 & 1 & 1.4 & 1 & 0 & 10.46 & ND \\
\hline 37 & 0 & 0 & -3.5 & 0 & 0 & 3.14 & 4.20 & 77 & 3 & 1,3 & 22.5 & 1 & 1 & Rain & ND \\
\hline 38 & 0 & 1 & -0.9 & 0 & 0 & 5.53 & 4.62 & 78 & 0 & 1 & 5.3 & 1 & 0 & 9.19 & ND \\
\hline 39 & 0 & 1 & 2.1 & 0 & 0 & 5.55 & 5.14 & 79 & 0 & 1 & 2.2 & 0 & 0 & 6.97 & ND \\
\hline 40 & 0 & 1 & -1.6 & 0 & 0 & 8.37 & 8.00 & 80 & 0 & 1 & 2.0 & 0 & 0 & 4.88 & ND \\
\hline
\end{tabular}


There were 74 ARG wind speed measurements corresponding to TMI wind retrievals from April 7 to June 6 of 1998. Among the 74 corresponding pairs, 44 were classified as conditions of moderately higher interference $(\mathrm{RFs}=1)$ by using the rain flag technique introduced in the SSM/I D-matrix algorithm. The other 30 cases were rain flag 0 points. For rain flag 0 points, the ARG confirmed that there were 13 wind only events, 16 cases with wind speed less than minimum detectable speed $\left(4 \mathrm{~m} \mathrm{~s}^{-1}\right)$, and one for noise sound level. For rain flag 1 points, the ARG confirmed that there were two rainy events, 23 wind only events, 16 cases with wind speed less than minimum detectable speed, and three for noise sound level. Therefore, 23 wind only points and two rainy events could not be identified accurately using the SSM/I D-matrix algorithm. In other words, the ability of weather classification for the ARG is $51.4 \%$ (38/74) and 34.2\% (13/38) for the SSM/I D-matrix algorithm. Worth noting is that the RFs technique almost malfunctioned in terms of rain recognition after May 15, 1998.

Among the 25 rain flag 1 points that were not consistent with the ARG observations, 18 points were classified as wind only cases using the TMI D-matrix algorithm $(\mathrm{RFt}=0)$, six rain flag 1 events, and one rainy point (number 47). Note this rainy point is not consistent with the ARG observation, which classified it as "wind only". In sum, the RFt technique increased acceptable data samples by 18 points. However, sole use of the TMI D-matrix algorithm means that accurate weather typing of the other six rain flag 1 points (numbers $25,47,51,61,62$, and 70) remains unknown.

According to ARG observations, numbers 25 and 47 were identified as rainy scenes. The other four points (numbers 51,61,62, and 70) were all wind only cases. Two microwave screening methods, the SI and CL methods, were used to determine accurate weather types for these uncertain points (see Fig. 2), the criterion being that the SI and CL methods must both identify this rain flag 1 point as either a rainy scene or a non-rainfall point. Results showed SI and CL identifying numbers 51, 61, 62, and 70 as non-rainfall cases and number 25 as a rainy scene. These weather classifications were all consistent with ARG observations.

In addition, the SI and CL methods both classified case number 47 as a rainy point corresponding with the RFt technique's findings. However, number 47 was classified as a nonrainfall point by the ARG over the sea surface where the retrieved surface wind speed of $15.52 \mathrm{~m} \mathrm{~s}^{-1}$ was extremely strong. At that time, active convections prevailed over the northern South China Sea. Case number 53 presented a familiar result, which is the ARG observation corresponding with the TRMM overpass \#2730 (19 May 23:55 UTC). It was noted that the difference between $\mathrm{Tb} 37 \mathrm{~V}$ and $\mathrm{Tb} 37 \mathrm{H}$ was $32.12 \mathrm{~K}$, and the $\mathrm{Tb} 19.4 \mathrm{H}$ was $191.53 \mathrm{~K}$. This suggests that this point fulfilled the criteria of rain flags 1 and 2 for the old rain flag technique. Therefore, the RFs technique cannot indicate a clear rain flag value for this sample. On the other hand, the RFt technique clearly identified this point as a rain flag 2 event (possible rain); and furthermore, with assistance from the SI and CL methods, this point can more clearly be claimed as a rainfall point.

Regarding statistics of wind measurements from the SCS3 buoy corresponding with TRMM overpasses, 80 corresponding pairs occurred from April 14 to June 30. Forty-six of the corresponding pairs were identified as conditions of moderately higher interference by the SSM/I D-matrix algorithm $(\mathrm{RFs}=1)$. The other 40 rain flag 0 points were consistent with SCS3 observations. The ability of the RFs technique to clarify weather is $42.5 \%$ (34/80). Worth 


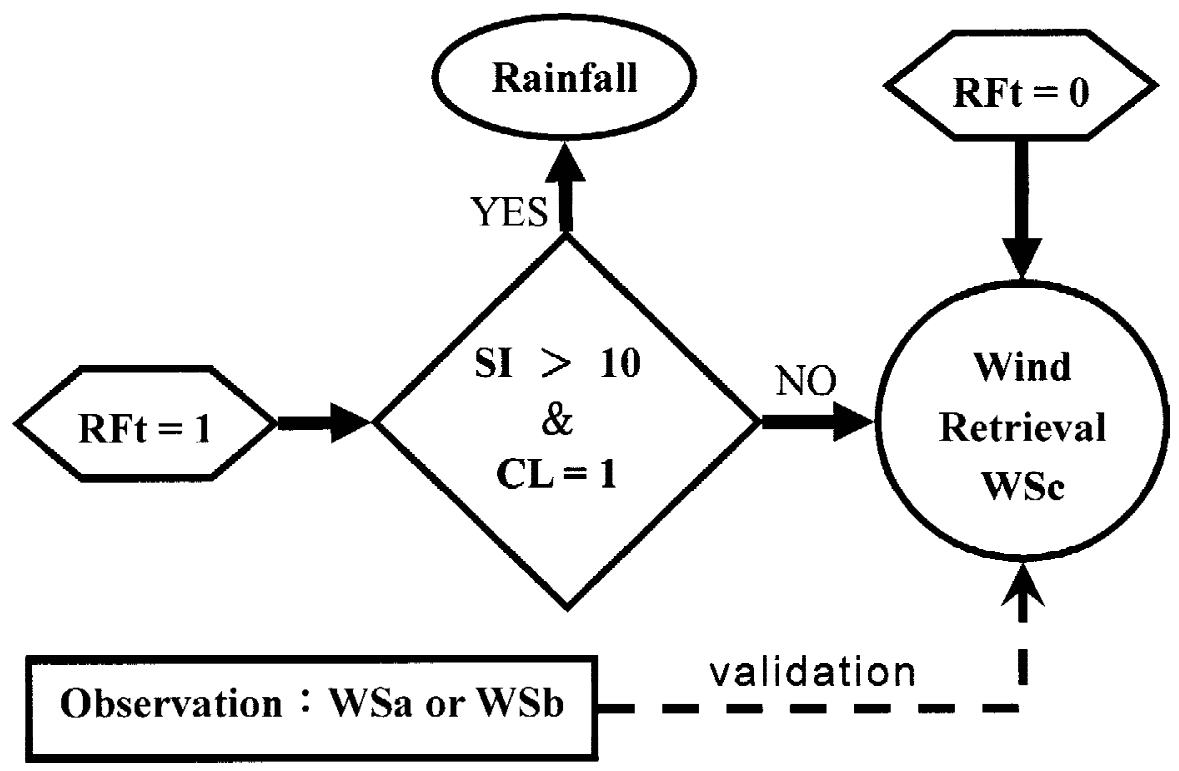

Fig. 2. The flowchart of surface wind retrievals.

noting is that this technique almost malfunctioned in terms of rain recognition after May 20, 1998.

Using the RFt technique, among the 46 rain flag 1 points observed, 40 were changed to rain flag 0 events, four remain rain at flag 1 , and the remaining two were rainfall points. These two rain points were numbers 69 and 77 within Table 4. SCS3 observed case number 77 as a rainfall scene; however, it also observed case number 69 as a non-rainfall scene. In addition, SCS3 measurements indicated that the 40 rain flag 0 points were all non-rainfall cases. Hence, for the SCS3 site, the RFt technique increased acceptable data samples by 40 points during this period of time.

As for the four rain flag 1 points, SCS3 observed three points as non-rainfall points (numbers 42,45 , and 70 ) and one point as a rainy point (number 43 ). Therefore, the four non-rainfall points (numbers 42, 45, 69, and 70) and one point (number 43) were not identified correctly using the RFt technique. Among the same four rain flag 1 points, the SI and CL methods identified three non-rainfall events (numbers 42,45 , and 70 ) and one rainfall point (the number 43). The results of weather classification were all consistent with SCS3 observations. The rain flag 3 point (number 69) should have been a non-rainfall point according to SCS3 observation. It is apparent then that with the assistance of the SI and CL methods accurate weather classification can be obtained for wind speed retrieval.

According to a report of the SCSMEX (Lau et al. 2000), during 1998, the earliest stage of summer monsoon onset occurred over the northern South China Sea around May 15 - 17, defined by the development of a steady low-level southwesterly and heavy precipitation. The 
summer monsoon developed over the entire South China Sea around May 20 - 25, signaled by a shift in the large-scale monsoon circulation pattern. Validation results reveal that the moist air significantly affects the RFs technique during this period of time.

Another finding is the significant advantage of adding the $10.7 \mathrm{GHz}$ measurements to the microwave wind speed retrieval technique. Moreover, in local usage, the validation results also show that the RFt technique might not thoroughly distinguish non-rainfall points from rain flag 1 points; however, with the assistance of the SI and CL methods, rain flag 1 points can be identified accurately.

The results also showed an improvement in increasing acceptable data samples of addition microwave screening methodologies to the TMI D-matrix algorithm. As for the quantitative comparison, Fig. 3 shows a scatter plot of TMI wind retrievals and ocean buoy wind observations listed in Tables 4 and 5. Only cases of wind speed weaker than $15 \mathrm{~m} \mathrm{~s}^{-1}$ were analyzed. Ninety-six points were used in the analysis (black dot: the SCS3 buoy, gray dot: the $\mathrm{ARG}$ ) with a root mean square of $1.34 \mathrm{~m} \mathrm{~s}^{-1}$. It is noted that TMI-retrieved surface wind speeds were overestimated or underestimated when ARG wind speeds were weaker or stronger than about $7 \mathrm{~m} \mathrm{~s}^{-1}$, respectively. This might have been because the TMI D-matrix algorithm was affected by surface foam effect (Wilheit and Chang 1980).

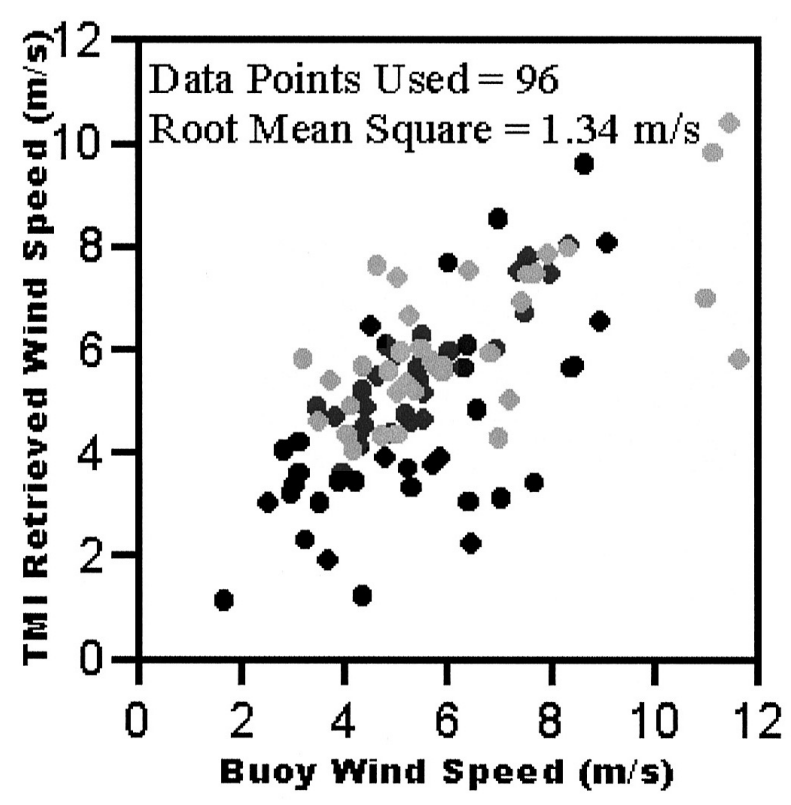

Fig. 3. A scatter plot of the ocean surface wind speeds retrieved by the TMI Dmatrix algorithm corresponding with the ocean buoy observations listed in Tables 4 and 5. Only cases of wind speed weaker than $15 \mathrm{~m} \mathrm{~s}^{-1}$ were analyzed. (black dot: the SCS3 buoy, gray dot: the ARG) 


\section{CONCLUSIONS}

The ocean surface wind retrieval technique using TMI data developed by Connor and Chang (2000) was validated and examined in this study using surface wind speed measurements from two ocean buoys. Using TMI data as inputs, according to the validation results, we found the TMI D-matrix algorithm was an improvement over the SSM/I D-matrix algorithm in the increase of acceptable data samples from rain flag 1 points, which originally could not be identified with the SSM/I D-matrix algorithm.

Although the TMI D-matrix algorithm effectively improved the SSM/I D-matrix algorithm for increasing acceptable data samples, some TMI points still remained rain flag 1 conditions. Since the TMI D-matrix algorithm might fail in rain scene recognition after the summer monsoon onset, assistance to its rain identification ability was conducted in this study using screening methods for screening out non-rainfall TMI points. With the assistance of the SI and CL methods for identifying non-rainfall points, these rain flag 1 points can be accurately recognized as either rainfall points or non-rainfall events. As to the quantitative comparison, only cases of wind speed weaker than $15 \mathrm{~m} \mathrm{~s}^{-1}$ were analyzed in this study, the root mean square is $1.34 \mathrm{~m} \mathrm{~s}^{-1}$.

The results of this study are significant for local usage of the profiling algorithm in providing a scheme for estimating ocean surface wind speeds over the South China Sea during the summer monsoon season.

Acknowledgments The authors would like to thank Dr. J. A. Nystuen for the acoustic rain gauge data, the US Tropical Rainfall Measuring Mission office for the TMI data, and Dr. David Tang for the ocean buoy data.

\section{REFERENCES}

Chen, W. J., and C. C. Li, 2000: Oceanic rain rate retrievals using TRMM microwave imager multi-channel brightness temperatures during the 1998 SCSMEX.Terr. Atmos. Ocean. Sci., 11, 765-788.

Connor, L. N., and P. S. Chang, 2000: Ocean surface wind retrievals using the TRMM microwave Imager. IEEE Trans. Geosci. Remote Sens., 38, 2009-2016.

Ferraro, R. R., N. Grody, and G. F. Marks, 1994: Effects of surface conditions on rain identification using the DMSP-SSM/I. Remote Sens. Rev., 11, 195-209.

Goodberlet, M. A., C. T. Swift, and J. C. Wilkerson, 1990: Ocean surface wind speed measurements of the special sensor microwave/ imager (SSM/I). IEEE Trans. Geosci. Remote Sens., 28, 823-827.

Grody, N. C., 1991: Classification of snow cover and precipitation using the Special Sensor Microwave Imager. J. Geophys. Res., 96, 7423-7435.

Hollinger, J. P., 1971: Passive microwave measurements of sea surface roughness.IEEE Trans. Geosci. Electron., GE-9, 165-169. 
Kummerow, C., W. Barnes, T. Kozu, J. Shiue, and J. Simpson, 1998: The tropical rainfall measuring mission (TRMM) sensor package. J. Atmos. Ocean. Technol., 15, 809-817.

Lau, K. M., Y. Ding, J. T. Wang, R. Johnson, T. Keenan, R. Cifelli, J. Gerlach, O. Thiele, T. Rickenbach, S. C. Tsay, and P. H. Lin, 2000: A report of the field operations and early results of the South China Sea Monsoon Experiment (SCSMEX). Bull. Am. Meteor. Soc., 81, 1261-1270.

Nystuen, J. A., and H. D. Selsor, 1997: Weather classification using passive acoustic drifters. J. Atmos. Ocean. Technol., 14, 656-666.

Simpson, J., C. Kummerow, W. K. Tao, and R. F. Adler, 1996: On the tropical rainfall measuring mission (TRMM). Meteor. Atmos. Phys., 60, 19-36.

Wilheit, T. T., and A. T. C. Chang, 1980: An algorithm for retrieval of ocean surface and atmospheric parameters from the observations of the scanning multichannel microwave radiometer. Radio Sci., 15, 525-544.

Li, C. C., and Liu, G. R., 2006: An empirical study of surface wind retrievals using the TMI over the South China Sea in the summer monsoon season. Terr. Atmos. Ocean. Sci.,17, 447-459. 